\section{A simple anaesthetic delivery system for magnetic resonance imaging}

To the Editor:

Continuous infusion propofol anaesthesia for paediatric patients undergoing magnetic resonance imaging (MRI), although effective, is problematic as most syringe pumps contain ferromagnetic parts that preclude close proximity to the MRI magnet. ${ }^{1-3}$ Long intravenous tubing and a syringe pump located outside the imaging room is cumbersome and incurs waste of propofol and intravenous supplies as the system has to be changed for each patient. $A$ free running intravenous solution mixed with propofol situated near the patient has been described, but ease of titration and immediate control are lacking, especially when dealing with infant patients.

We describe the use of a remote "bridging" pump that is hydraulically driven by a commercially available syringe pump (Graseby 3400) (Figure 1). The remote bridging pump (Figure 2), located alongside the patient, consists of two $60 \mathrm{ml}$ syringes mounted on a wooden track with the plungers opposed. One syringe, loaded with the anticipated volume of propofol required, is connected via an extension to the patient's intravenous catheter. The other syringe, filled with sufficient water to establish contact between the two syringe plungers, is connected via water filled

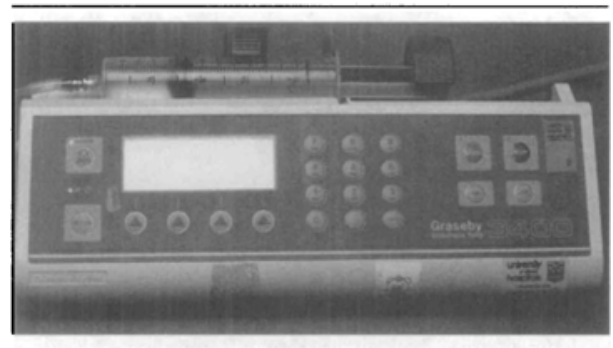

FIGURE 1 The remote "bridging" pump is hydraulically driven by a commercially available syringe pump (Graseby 3400 ).

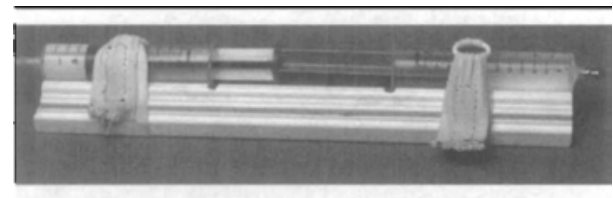

FIGURE 2 The remote bridging pump located alongside the patient consists of two $60 \mathrm{ml}$ syringes mounted on a wooden track with the plungers opposed. non-compliant tubing (super tygon arterial line tubing is ideal) of sufficient length to reach a second water-filled $60 \mathrm{ml}$ syringe mounted in a syringe pump located in the control room. Hydraulic action of the water-filled syringes drives the propofol syringe on a volume for volume basis allowing accurate drug administration. At the completion of imaging, the propofol syringe and intravenous extension are discarded and replacements readied for the next patient.

\section{John Koller MD FRCPC \\ Robert Seal MD FRCPC \\ University of Alberta Hospital \\ Edmonton, Alberta}

\section{REFERENCES}

1 Frankwille DD, Spear RM, Dyck JB. The dose of propofol required to prevent children from moving during magnetic resonance imaging. Anesthesiology 1993; 79 : $953-8$.

2 Bloomfield EL, Masaryk T], Caplin A, et al. Intravenous sedation for MR imaging of the brain and spine in children: pentobarbital versus propofol. Radiology 1993; 186: 93-7.

3 Kain ZN, Gaal DJ, Kain TS, Jaeger DD, Rimar S. A first-pass cost analysis of propofol versus barbiturates for children undergoing magnetic resonance imaging. Anesth Analg 1994; 79: 1102-6. 